\title{
Effects of blockade of fast and slow inward current channels on ventricular fibrillation in the
} pig heart

\author{
Adrian J Stewart, J Desmond Allen, Adrian B Devine, A A Jennifer Adgey
}

\begin{abstract}
Objective-To determine the contribution of fast and slow inward channels to the electrocardiogram (ECG) of ventricular fibrillation.
\end{abstract}

Methods-Ventricular fibrillation was induced by endocardial electrical stimulation in pigs anaesthetised with pentobarbitone sodium (30 mg/kg intravenously). ECGs simultaneously recorded from the body surface (lead II) and from the endocardium were studied by power spectrum analysis $(0-40 \mathrm{~Hz})$.

Results-The mean (SEM) dominant frequency of fibrillation $(9.0(1 \cdot 1) \mathrm{Hz}$ in lead II at $0-40$ s) did not change significantly with time in pigs given intravenous saline. However, the dominant frequency was significantly reduced by intravenous pretreatment with the class I antiarrhythmic drugs, lignocaine $(3 \mathrm{mg} / \mathrm{kg}, 6.5(0.5) \mathrm{Hz}$; $10 \mathrm{mg} / \mathrm{kg}, 4 \cdot 2(0.6) \mathrm{Hz})$, mexiletine (3 $\mathrm{mg} / \mathrm{kg}, 6.2(0.4) \mathrm{Hz} ; 10 \mathrm{mg} / \mathrm{kg}, 5.5(0.4)$ $\mathrm{Hz})$, and disopyramide $(2.5 \mathrm{mg} / \mathrm{kg}, 5.4$ $(0.6) \mathrm{Hz}$ ). After flecainide (3 mg/kg, 6.9 $(0.5) \mathrm{Hz})$ the reduction in frequency was not significant. Similar data were obtained with endocardial recordings. In contrast pre-treatment with verapamil $(0.2 \mathrm{mg} / \mathrm{kg}, 11.7(0.8) \mathrm{Hz}$; and $1.0 \mathrm{mg} / \mathrm{kg}$, $12.9(1.6) \mathrm{Hz})$ produced a significantly higher dominant frequency of fibrillation than saline and widened the bandwidth of frequencies around the dominant frequency.

Conclusions-These results indicate that voltage-dependent sodium channel currents contribute to the rapid frequencies of ventricular fibrillation. Blockade of $\mathbf{L}$ type inward calcium channel activity increases the fibrillation frequency and fractionates the frequencies of the fibrillation wavefronts.

(Heart 1996;76:513-519)

Physiology, and Therapeutics and Pharmacology, The Queen's University, and Regional Medical Cardiology Centre, Royal Victoria Hospital, Belfast A J Stewart J D Allen

J B Devine

A B Devine
A A J Adgey

Correspondence to: Professor A A J Adgey, Regional Medical Cardio Centre, Royal Victoria
Hospital, Belfast BT12 6BA Hospital, Belfast BT12 6BA. 6 August 1996 tion remains controversial. In this arrhythmir the activation frequencies of individual myocytes are extremely rapid, and may exceed 7-11 Hz. ${ }^{12}$ Studies using multiple epicardial ${ }^{3}$ and intramural electrodes ${ }^{2}$ show that in the early stages of fibrillation, ventricular activation fronts recorded on the epicardial surface are more organised than is suggested by the body surface electrocardiogram (ECG).

Fast Fourier transform analysis enables the relative contributions of different frequencies to a complex waveform to be assessed as the power spectrum (where power is proportional to amplitude squared). Such analyses of body surface and endocardial ECG recordings of ventricular fibrillation indicate that despite the fractionated electrical activity in the myocardium, the clinically recognisable periodicity of the fibrillation waveform is dominated by a narrow band of frequencies. ${ }^{4-9}$ The dominant or peak frequency is obtained from the spectrum. The coherence of the signal around this dominant frequency is estimated by the width of the frequency band between the frequencies above and below this peak where the signal power is $10 \mathrm{~dB}$ less than that for the dominant frequency. A more fractionated waveform should have a wider range of frequencies.

The fast Fourier transform method has been used in our unit to study ventricular fibrillation after acute myocardial infarction in patients and its relation to successful resuscitation. ${ }^{7}$ We have shown that the likelihood of successful resuscitation increased with a dominant frequency greater than $5 \mathrm{~Hz}$. Frequencies less than $5 \mathrm{~Hz}$ were associated with nonsurvival.

The actions of class I antiarrhythmic drugs on the cardiac voltage-dependent sodium channels vary ${ }^{10}$ because their electrophysiological effects are both voltage and rate dependent, ${ }^{11}{ }^{12}$ and they may change with myocardial $\mathrm{pH}$. The subgroups IA, IB, and $\mathrm{IC}^{10}{ }^{13}$ indicate different dissociation constants for binding to the voltage-dependent sodium channels, with time constants of $<1 \mathrm{~s}$ for class IB (fast), $1-10 \mathrm{~s}$ for IA (intermediate), and $>10 \mathrm{~s}$ for IC (slow). ${ }^{1214}$ However, because the effects of these drugs will differ in ischaemic and nonischaemic myocardium and at fast stimulation rates compared with slow sinus rhythm, it is difficult to predict their effects in ventricular fibrillation.

Calcium ions and the L-type calcium channels have an important role in both the initiation and maintenance of ventricular fibrillation. ${ }^{1516}$ Moreover, the accumulation of intracellular calcium during ventricular fibrillation has been linked to the development of post-fibrillation dysfunction. ${ }^{16-19}$ Verapamil, which blocks the L-type calcium channels and reduces the accumulation of calcium in acutely ischaemic myocardium, also decreases 
the incidence of ventricular fibrillation ${ }^{20}$ and delays the release of potassium ${ }^{21}$ after coronary artery occlusion.

What effects do these different drug groups have during established ventricular fibrillation, when the hypoxic and acidotic myocardial cells are subject to multiple rapid depolarisations at low membrane potential? To study this requires a suitable animal model for the clinical disorder. Isolated in vitro tissue preparations cannot mimic the clinical state, because sustained fibrillation requires a critical mass of myocardium. The dog heart shows a dramatic fall in the dominant frequency with duration of ventricular fibrillation in the endocardium but not the epicardium. ${ }^{3619}$ This fall in frequency is less marked in the human. ${ }^{7}$ The pig heart seems to be a more suitable model because it shows a slower frequency, similar to the human, and slower changes in dominant frequency with time. ${ }^{22}$ Hence in the present study the electrophysiological events during ventricular fibrillation were studied in the pig heart, using simultaneous recordings to determine the power spectrum of the fibrillation waveform from the body surface and the endocardium. This paper reports the effects of sodium and calcium channel blockade on established ventricular fibrillation in the pig heart.

\section{Methods}

Pigs of both sexes $(24-44 \mathrm{~kg})$ were sedated with azaperone ( $5 \mathrm{mg} / \mathrm{kg}$ intramuscularly). Anaesthesia was induced with sodium pentobarbitone $(30 \mathrm{mg} / \mathrm{kg}$ intravenously), and maintained with further doses $(2-5 \mathrm{mg} / \mathrm{kg}$ intravenously) as required. Ventilation was maintained with room air (18 per min; tidal volume $10-12.5 \mathrm{ml} / \mathrm{kg}$; Palmer Ideal pump) through an endotracheal tube. After cannulation of the right femoral artery the arterial blood pressure (Gould Statham) was recorded with the ECG (lead II) on a multichannel recorder (Hewlett-Packard). Oesophageal temperature was monitored with an electronic thermometer (Comark). An ear or femoral vein was cannulated for drug administration.

Two endocardial pacing catheters were advanced from the external jugular vein (under fluoroscopic control) to the apex of the right ventricle. One catheter was used to initiate ventricular fibrillation and the other to record the endocardial ECG during ventricular fibrillation. After surgery the animals were allowed to stabilise for a one hour control period. Arterial blood samples for determination of $\mathrm{P}_{\mathrm{a}} \mathrm{O}_{2}, \quad \mathrm{P}_{\mathrm{a}} \mathrm{CO}_{2}, \quad$ and $\mathrm{pH}$ (Instrumentation Laboratories) were taken during the control period and immediately before the induction of ventricular fibrillation.

\section{DRUG GROUPS}

The 45 pigs were randomly assigned to one of nine groups. Each drug was administered intravenously as a $20 \mathrm{ml}$ volume over five min and ventricular fibrillation was induced five min later. Arterial blood samples were taken before treatment and at the onset of fibrillation and stored at $-80^{\circ} \mathrm{C}$ for determination of the plasma drug concentration by high pressure liquid chromatography.

No drug-Control $0.9 \%$ saline

Class $I A$-Disopyramide $2.5 \mathrm{mg} / \mathrm{kg}^{23}$

Class IB-Lignocaine $3 \mathrm{mg} / \mathrm{kg}$, ${ }^{24}$ lignocaine $10 \mathrm{mg} / \mathrm{kg}$

Class IB-Mexiletine $3 \mathrm{mg} / \mathrm{kg}$, mexiletine $10 \mathrm{mg} / \mathrm{kg}$

Class IC-Flecainide $3 \mathrm{mg} / \mathrm{kg}^{25}$

Class IV-Verapamil $0 \cdot 2 \mathrm{mg} / \mathrm{kg}^{20}$ verapamil $1 \mathrm{mg} / \mathrm{kg}$

Ventricular fibrillation was induced by brief endocardial stimulation of the right ventricle $(100 \mathrm{~Hz}, 10 \mathrm{~V}, 5 \mathrm{~ms}$ pulses; Grass Instruments S4). If fibrillation was not induced with this stimulus, the voltage of the pulses was increased in steps of $5 \mathrm{~V}$ to a maximum of $30 \mathrm{~V}$. The onset of ventricular fibrillation was confirmed by the ECG record and the fall in arterial blood pressure. The ECG signals of ventricular fibrillation from lead II and endocardium were recorded on tape (15-20 $\mathrm{min}$ ) for subsequent analysis. At the end of this period of fibrillation the heart was excised and weighed.

\section{FREQUENCY ANALYSIS}

The ECG signals of ventricular fibrillation from lead II and the endocardial lead were separately amplified (Hellige Multiskriptor), digitised with a purpose built A-D converter (10 bit, $240 \mathrm{~Hz}$, anti-aliasing filter at $44 \mathrm{~Hz}$ ), and recorded on magnetic tape. A spectrum analyser (Type 2031, Bruel \& Kjaer) performed fast Fourier transform analysis on the reconstituted fibrillation signal. The signal was monitored throughout the analysis with an oscilloscope (Gould) to avoid artefact. A power spectrum, the logarithmic plot of the root mean square power against frequency, was obtained, with a reference level of $1 \mu \mathrm{V}$. Individual $4 \mathrm{~s}$ periods of ventricular fibrillation gave power spectra with a frequency range of $0-100 \mathrm{~Hz}$ and $0.25 \mathrm{~Hz}$ resolution. A Hanning window was used to reduce the error in frequency resolution caused by analysing a finite number of samples. Analysis of test frequencies recorded through the ECG amplifier showed a flat frequency response from $<0.25$ to $40 \mathrm{~Hz}$ for the system. Ten sequential power spectra were averaged to give a spectrum for each $40 \mathrm{~s}$ period of ventricular fibrillation. Using the screen cursor we determined the peak or dominant frequency, the corresponding amplitude (power in decibels, $\mathrm{dB}$ ), and the dispersion of frequencies around this peak frequency ( $\pm 10 \mathrm{~dB}$ limits). Each power spectrum was printed (Bruel \& Kjaer Type 2308 Recorder)

\section{STATISTICAL ANALYSIS}

The results are expressed as the mean (SEM). Comparison between the means of the different treatment groups was made by analysis of variance and Duncan's multiple range test (Oneway; SPSS). Further analyses used both parametric ( $t$ tests) and non-parametric tests (Mann-Whitney U and Kruskal-Wallis). The null hypothesis was that there were no signifi- 
Table 1 Basic measurements before induction of ventricular fibrillation (Pre-VF)

\begin{tabular}{|c|c|c|c|c|}
\hline \multirow{2}{*}{$\begin{array}{l}\text { Treatment } \\
(\mathrm{mg} / \mathrm{kg})\end{array}$} & \multirow{2}{*}{$\begin{array}{l}\text { Body weight } \\
(\mathrm{kg})\end{array}$} & \multirow{2}{*}{$\begin{array}{l}\text { Heart weight } \\
(g)\end{array}$} & \multicolumn{2}{|c|}{ Pre-VF arterial blood } \\
\hline & & & $p H$ & $\mathrm{pCO}_{2} \mathrm{~mm} \mathrm{Hg}$ \\
\hline No drug & $32 \cdot 4(2 \cdot 5)$ & $158(10)$ & $7.42(0.02)$ & $36(2)$ \\
\hline Disopyramide $(2.5)$ & $37.0(1.5)$ & $189(4)$ & $7.41(0.01)$ & $37(1)$ \\
\hline Lignocaine (3) & $37 \cdot 0(2 \cdot 8)$ & $194(5)$ & $7.45(0.02)$ & $32(1)$ \\
\hline Lignocaine (10) & $34 \cdot 6(2 \cdot 0)$ & $177(10)$ & $7.43(0.04)$ & $35(2)$ \\
\hline Mexiletine (3) & $32 \cdot 4(1 \cdot 4)$ & $179(8)$ & $7.42(0.02)$ & $35(2)$ \\
\hline Mexiletine (10) & $35.6(1.8)$ & 179 (13) & $7.45(0.02)$ & $37(1)$ \\
\hline Flecainide (3) & $35 \cdot 2(0 \cdot 2)$ & $181(3)$ & $7.38(0.02)$ & $37(1)$ \\
\hline Verapamil $(0 \cdot 2)$ & $36 \cdot 0(0 \cdot 8)$ & $168(7)$ & $7.45(0.04)$ & $33(3)$ \\
\hline Verapamil $(1 \cdot 0)$ & $33.0(1.4)$ & $177(10)$ & $7.43(0.02)$ & $37(2)$ \\
\hline
\end{tabular}

Mean values (SEM) for the nine groups of five pigs.

None of the treatment groups showed a significant difference from the values for the control "no drug" group.

Table 2 Haemodynamic measurements, before (Pre-drug) and after drug treatment (Pre-VF)

\begin{tabular}{lcccc}
\hline $\begin{array}{l}\text { Treatment } \\
\text { (mg/kg) }\end{array}$ & $\begin{array}{l}\text { Pre-drug } \\
\text { heart rate } \\
\text { (beats/min) }\end{array}$ & $\begin{array}{l}\text { Pre-VF } \\
\text { heart rate } \\
\text { (beats/min) }\end{array}$ & $\begin{array}{l}\text { Pre-drug } \\
\text { systolic BP } \\
(\mathrm{mm} \mathrm{Hg})\end{array}$ & $\begin{array}{l}\text { Pre-VF } \\
\text { systolic BP } \\
(\mathrm{mm} \mathrm{Hg})\end{array}$ \\
\hline No drug & $127(19)$ & $122(18)$ & $107(12)$ & $100(7)$ \\
Disopyramide (2.5) & $92(8)$ & $93(8)$ & $100(5)$ & $95(5)$ \\
Lignocaine (3) & $109(6)$ & $96(6)$ & $97(3)$ & $93(4)$ \\
Lignocaine (10) & $93(4)$ & $78(5)^{\star \star}$ & $98(5)$ & $82(8)$ \\
Mexiletine (3) & $99(7)$ & $93(7)$ & $91(4)$ & $90(3)$ \\
Mexiletine (10) & $98(11)$ & $92(14)$ & $97(4)$ & $88(8)$ \\
Flecainide (3) & $105(12)$ & $106(6)$ & $110(10)$ & $90(7)$ \\
Verapamil (0.2) & $130(15)$ & $135(12)$ & $113(6)$ & $101(7)$ \\
Verapamil (1.0) & $113(3)$ & $115(5)$ & $100(9)$ & $74(6)^{\star}$ \\
\hline
\end{tabular}

Mean values (SEM) for the nine groups of five pigs.

${ }^{\star} P<0.05 ;{ }^{\star \star} P<0.01$ compared with "no drug" group.

cant differences with time between the values observed within and between the different treatment groups. The level of significance for rejection of the null hypothesis was $\mathrm{P}<0.05$.

\section{Results}

The mean body weights, heart weights, and the oesophageal temperature (mean 36.5 $(0 \cdot 1)^{\circ} \mathrm{C}$ ) were similar in the nine groups (table 1). Arterial blood $\mathrm{pH}, \mathrm{P}_{\mathrm{a}} \mathrm{CO}_{2}$ and $\mathrm{P}_{\mathrm{a}} \mathrm{O}_{2}$ did not differ significantly between the nine groups either during the control period (not shown) or five min after the administration of antiarrhythmic drug (table 1). Initial haemodynamic variables were also comparable, with no significant differences for heart rate and systolic (or diastolic) arterial blood pressures before drug administration in the nine groups (table 2).

In the pre-drug control period the electrophysiological variables of the ECG (lead II) did not differ significantly between any of the

Figure 1 Dominant frequencies of fibrillation in lead II over periods $0-40 \mathrm{~s}$ and 160-200s after saline, lignocaine $(3$ or 10 $\mathrm{mg} / \mathrm{kg}$ ), or mexiletine ( 3 or $10 \mathrm{mg} / \mathrm{kg}$ ). Mean (SEM) is shown for groups of five pigs. Significant differences from values in the " $n$ o drug" group are indicated: $\star P<0.05 ; \star \star P<0.01$.

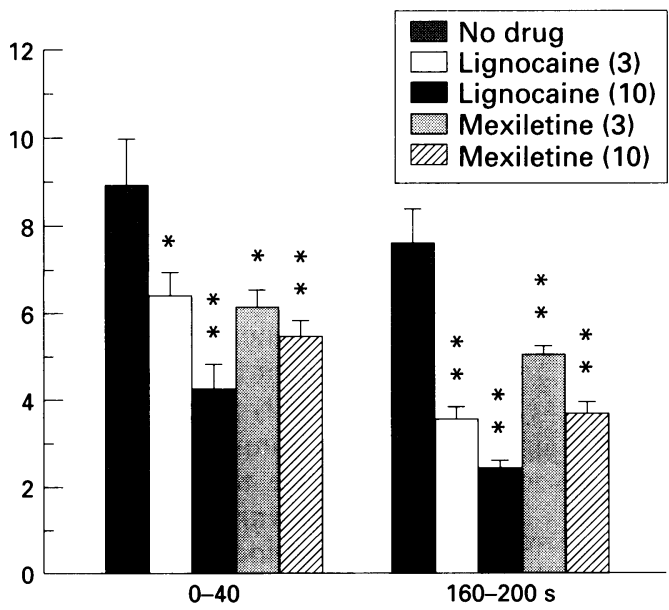

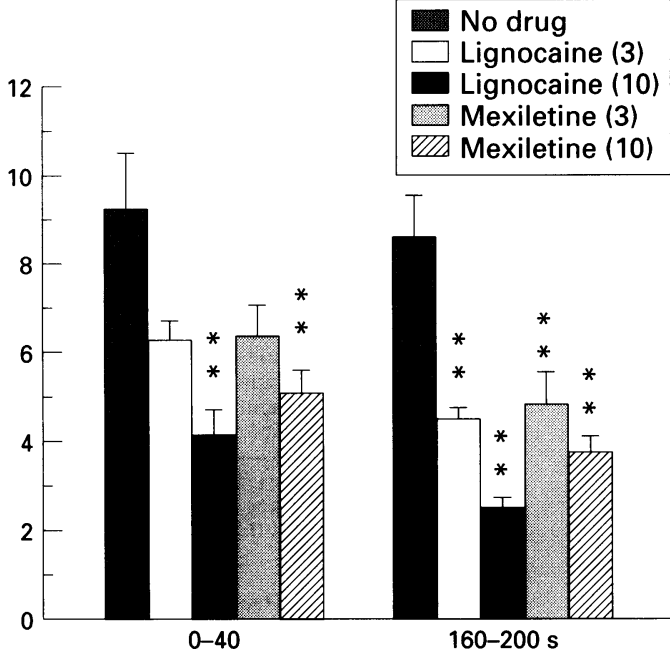

Figure 2 Dominant frequencies of fibrillation in the endocardium after saline, or lignocaine ( 3 or $10 \mathrm{mg} / \mathrm{kg}$ ) or mexiletine (3 or $10 \mathrm{mg} / \mathrm{kg}$ ).

eight active treatment groups and that in the control group (PR interval 100 (8) ms, QRS duration 62 (10) $\mathrm{ms}$, QT interval 352 (42) $\mathrm{ms})$. After antiarrhythmic drug administration there were still no significant differences between the control group and the eight active treatment groups with respect to these measurements.

Ventricular fibrillation was induced with a single burst of stimulation at $10 \mathrm{~V}$ in all animals in the "no drug" control group and in the two groups pre-treated with verapamil. All groups treated with class I antiarrhythmic drugs showed an increase in the threshold voltage needed to cause fibrillation, which was significantly greater than the "no drug" control values after treatment with the class IB drugs, lignocaine $(3 \mathrm{mg} / \mathrm{kg}, 17 \cdot 0(1.2) \mathrm{V} ; 10$ $\mathrm{mg} / \mathrm{kg}, 23.0(2.0) \mathrm{V} ; \mathrm{P}<0.01)$ and mexiletine $(10 \mathrm{mg} / \mathrm{kg}, 17.0(3.4) \mathrm{V} ; \mathrm{P}<0.05)$.

Generally the power spectra of ventricular fibrillation, whether recorded from the body surface (lead II) or simultaneously from the right ventricular endocardium, were initially similar and showed similar changes with time in dominant frequencies and $\pm 10 \mathrm{~dB}$ bandwidths. As expected, the power (dB) of the dominant frequency, proportional to the (amplitude) squared, was consistently higher in the signal from the endocardial lead.

In the control group the mean dominant frequency recorded from lead II, which was initially $9.0(1 \cdot 1) \mathrm{Hz}$ (fig 1), did not drop significantly after $200 \mathrm{~s}$ of fibrillation $(7 \cdot 7(0 \cdot 7)$ $\mathrm{Hz}$ ). The mean dominant frequency in the endocardial lead was similar at $0-40 \mathrm{~s}$ to that in lead II (table 3 ) and remained high after 200 s (fig 2).

\section{DRUGS ACTING ON VOLTAGE-DEPENDENT} SODIUM CHANNELS

The changes in the dominant frequency of fibrillation (0-200 s) in the control group and the active treatment groups are shown for lead II (figs 1 and 3) and the endocardial lead (figs 2 and 4). Data obtained for fibrillation lasting 200 to $400 \mathrm{~s}$ are not shown. 
Table 3 Frequency analyses of the first 40 seconds of ventricular fibrillation

\begin{tabular}{|c|c|c|c|c|c|c|}
\hline \multirow[b]{2}{*}{$\begin{array}{l}\text { Treatment } \\
(\mathrm{mg} / \mathrm{kg})\end{array}$} & \multicolumn{3}{|l|}{ Lead II } & \multicolumn{3}{|c|}{ Endocardial lead } \\
\hline & $\begin{array}{l}\text { Dominant } \\
\text { frequency } \\
(\mathrm{Hz})\end{array}$ & $\begin{array}{l}\text { Peak } \\
\text { power } \\
(d B)\end{array}$ & $\begin{array}{l}-10 \mathrm{~dB} \\
\text { bandwidth } \\
(\mathrm{Hz})\end{array}$ & $\begin{array}{l}\text { Dominant } \\
\text { frequency } \\
(\mathrm{Hz})\end{array}$ & $\begin{array}{l}\text { Peak } \\
\text { power } \\
(d B)\end{array}$ & $\begin{array}{l}-10 \mathrm{~dB} \\
\text { bandwidth } \\
(\mathrm{Hz})\end{array}$ \\
\hline $\begin{array}{l}\text { No drug } \\
\text { (0.9\% saline) }\end{array}$ & $9 \cdot 0(1 \cdot 1)$ & $99 \cdot 7(1 \cdot 5)$ & $4 \cdot 4(0 \cdot 3)$ & $9 \cdot 3(1 \cdot 3)$ & $106 \cdot 5(1 \cdot 0)$ & $4 \cdot 2(0 \cdot 8)$ \\
\hline Disopyramide $(2.5)$ & $5 \cdot 4(0 \cdot 6)^{\star \star}$ & $104 \cdot 8(0 \cdot 8)$ & $3.7(0.2)$ & $6 \cdot 7(0.6)$ & $106 \cdot 4(2 \cdot 0)$ & $3.4(0.5)$ \\
\hline Lignocaine (3) & $6.5(0.5)^{\star}$ & $104 \cdot 2(0 \cdot 8)$ & $2.9(0.5)$ & $6 \cdot 3(0 \cdot 4)$ & $106.0(1.6)$ & $3.3(0.3)$ \\
\hline Lignocaine (10) & $4 \cdot 2(0 \cdot 6)^{\star \star}$ & $107.5(2 \cdot 2)^{\star \star}$ & $2 \cdot 0(0 \cdot 2)^{\star}$ & $4 \cdot 1(0 \cdot 6)^{\star \star}$ & $110.5(0.7)^{\star}$ & $1.8(0.2)^{\star}$ \\
\hline Mexiletine (3) & $6 \cdot 2(0 \cdot 4)^{\star}$ & $104 \cdot 1(0 \cdot 9)$ & $3.2(0.4)$ & $6.4(0.7)$ & $108.9(1.3)$ & $2 \cdot 8(0.5)$ \\
\hline Mexiletine (10) & $5 \cdot 5(0 \cdot 4)^{\star \star}$ & $106.5(1.9)^{\star}$ & $2 \cdot 6(0 \cdot 3)$ & $5 \cdot 1(0 \cdot 5)^{\star \star}$ & $109 \cdot 8(1 \cdot 1)$ & $2 \cdot 0(0.4)^{\star}$ \\
\hline Flecainide (3) & $6.9(0.5)$ & $105 \cdot 2(2 \cdot 7)^{\star}$ & $3 \cdot 0(0 \cdot 7)$ & $7 \cdot 0(0 \cdot 7)$ & $109.5(1.8)$ & $3 \cdot 2(0 \cdot 8)$ \\
\hline Verapamil $(0 \cdot 2)$ & $11.7(0.8)^{\star}$ & $98.4(0.8)$ & $5.5(0.7)$ & $10 \cdot 3(1 \cdot 3)$ & $103.9(0.7)$ & $7 \cdot 8(1 \cdot 0)^{\star \star}$ \\
\hline Verapamil $(1 \cdot 0)$ & $12.9(1.6)^{\star \star}$ & $96.7(1.8)$ & $6 \cdot 5(1 \cdot 6)^{\star}$ & $12.0(1.5)$ & $102 \cdot 2(0 \cdot 7)^{\star}$ & $9 \cdot 8(1 \cdot 0)^{\star \star}$ \\
\hline
\end{tabular}

Mean (SEM) for dominant frequency and its amplitude and $-10 \mathrm{~dB}$ frequency bandwidth in the nine treatment groups for both the

surface lead II and endocardial ECG.

Pre-treatment with the class IA drug, disopyramide $(2.5 \mathrm{mg} / \mathrm{kg}$, plasma concentration $1.5(0 \cdot 2) \mu \mathrm{g} / \mathrm{ml})$ reduced the initial dominant frequency of ventricular fibrillation in lead II (table 3), with no further reduction over the $200 \mathrm{~s}$ period (fig 3). The dominant frequency from the endocardial lead was not reduced significantly in the first $40 \mathrm{~s}$, although it fell after $80 \mathrm{~s}$ and remained significantly lower than the "no drug" group in the remaining record (fig 4). This was the only group with a significant difference in dominant frequency between lead II and the endocardium (for 0-40 s, P < 0.05; table 3).

The class IB drugs had a marked depressant effect on the dominant frequency of ventricular fibrillation. The lower dose of lignocaine ( 3 $\mathrm{mg} / \mathrm{kg}$, plasma concentration $3.3(0.5) \mu \mathrm{g} / \mathrm{ml})$ had little effect on heart rate and blood pressure before ventricular fibrillation (table 2), but reduced the dominant frequency of fibrillation in both lead II (fig 1) and the endocardium (fig 3).

After lignocaine $(10 \mathrm{mg} / \mathrm{kg}$, plasma concentration $15.8(1 \cdot 2) \mu \mathrm{g} / \mathrm{ml})$ there was a fall in heart rate before the induction of fibrillation (table 2). The dominant frequency from lead II was low initially (table 3) and fell further after $200 \mathrm{~s}$ of fibrillation (fig 1). The endocardial lead gave similar results (fig 2 ).

The low dose of mexiletine $(3 \mathrm{mg} / \mathrm{kg}$ ) also

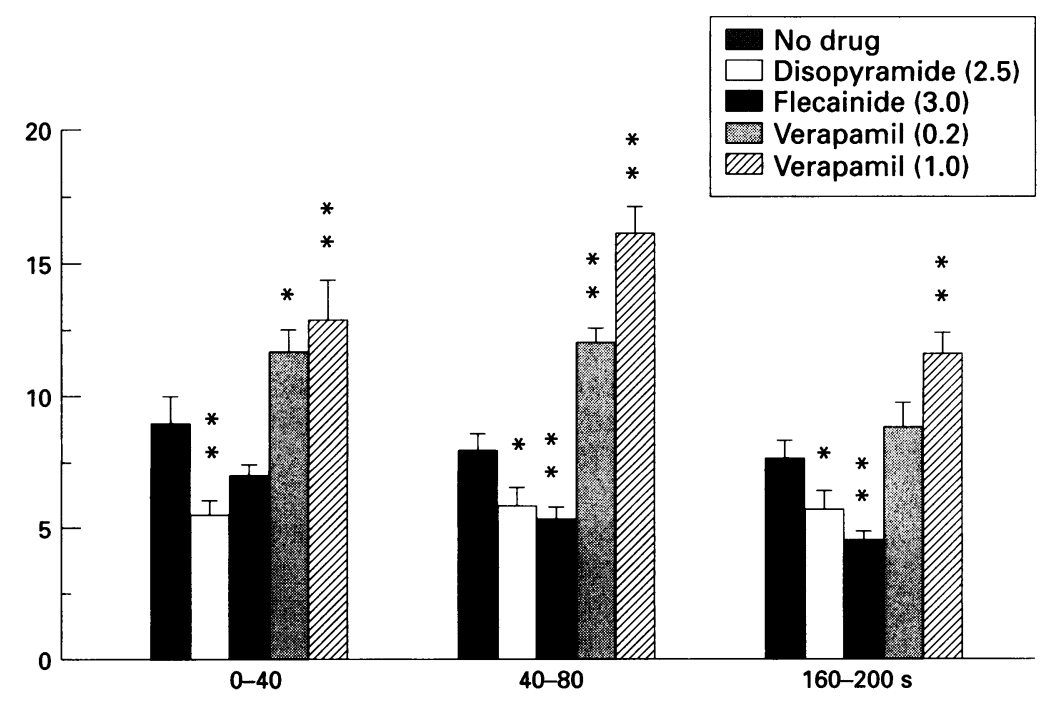

Figure 3 Dominant frequencies of three periods of ventricular fibrillation recorded from lead II of the ECG in groups of five pigs given either saline (no drug), disopyramide (2.5 $\mathrm{mg} / \mathrm{kg})$, flecainide (3 $\mathrm{mg} / \mathrm{kg})$, or verapamil $(0 \cdot 2$ or $1.0 \mathrm{mg} / \mathrm{kg})$. reduced the dominant frequency of fibrillation in lead II (table 3 ) and the endocardium. With mexiletine $(10 \mathrm{mg} / \mathrm{kg})$ the dominant frequency was reduced initially in both lead II and the endocardium (table 3 ), and continued to fall with duration of the fibrillation (figs 1 and 2). Concentrations of mexiletine could not be determined reliably in pig plasma. After pretreatment with the larger doses $(10 \mathrm{mg} / \mathrm{kg})$ of the class I antiarrhythmic drugs, lignocaine and mexiletine, the lower dominant frequency of fibrillation and increased peak power were accompanied by a narrowing of the $-10 \mathrm{~dB}$ bandwidths in both lead II and the endocardium (table 3), suggesting increased coherence of the fibrillation signal.

The class $1 \mathrm{C}$ drug, flecainide $(3 \mathrm{mg} / \mathrm{kg}$, plasma concentration $2 \cdot 2(0 \cdot 3) \mu \mathrm{g} / \mathrm{ml})$ did not significantly reduce the dominant frequency of ventricular fibrillation in the initial $40 \mathrm{~s}$ (table 3) although it did fall significantly after $80 \mathrm{~s}$ of fibrillation in lead II (fig 3), and fell thereafter in the endocardium (fig 4).

The mean peak power of ventricular fibrillation recorded from lead II (table 3) was significantly higher than the control "no drug" value after pre-treatment with lignocaine (10 $\mathrm{mg} / \mathrm{kg}$ ), mexiletine $(10 \mathrm{mg} / \mathrm{kg})$, and flecainide $(3 \mathrm{mg} / \mathrm{kg}$ ). In all groups the power of the endocardial signal was bigger than that from lead II, but only after pre-treatment with lignocaine $(10 \mathrm{mg} / \mathrm{kg}$ ) was this increased significantly above "no drug" endocardial values. The only significant difference in dominant frequency between lead II and the endocardial recordings was seen after pre-treatment with disopyramide, as noted above.

EFFECTS OF VERAPAMIL

The higher dose of verapamil ( $1 \mathrm{mg} / \mathrm{kg}$, plasma concentration 261 (81) $\mathrm{ng} / \mathrm{ml}$ ), had cardiovascular effects, with a drop in both systolic and diastolic arterial blood pressures compared with pre-drug values $(P<0.05$, table 2) and an increase in the $P R$ interval (106 (6) to $132(8), P<0.05)$. After the higher dose of verapamil $(1 \mathrm{mg} / \mathrm{kg})$, the dominant frequency of fibrillation in lead II was initially increased compared with the control group (table 3). The frequency continued to rise to a peak at $80 \mathrm{~s}$ (fig 3), before falling towards control group levels at $280 \mathrm{~s}$. The endocardial recording gave similar results, with an initial frequency significantly higher 


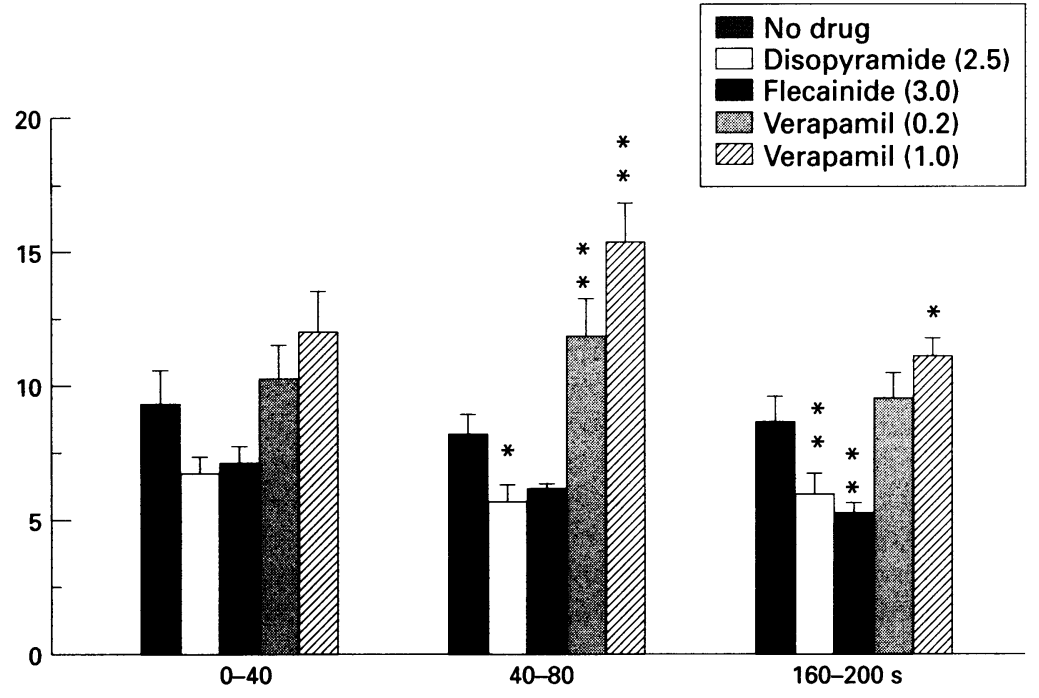

Figure 4 Dominant frequencies of three durations of ventricular fibrillation recorded from the endocardium in pigs given either saline (no drug), disopyramide $(2 \cdot 5 \mathrm{mg} / \mathrm{kg})$, flecainide $(3 \mathrm{mg} / \mathrm{kg})$, or verapamil $(0 \cdot 2$ or $1.0 \mathrm{mg} / \mathrm{kg})$.

than the control, a peak frequency at $80-120 \mathrm{~s}$ $(16.0(0.8) \mathrm{Hz})$, nearly twice as high as the control group $(8 \cdot 1(1 \cdot 1) \mathrm{Hz}$ (fig 4)), and a return towards control group values at $320 \mathrm{~s}$.

After the low dose of verapamil $(0.2 \mathrm{mg} / \mathrm{kg}$, plasma concentration 49 (3) $\mathrm{ng} / \mathrm{ml}$ ) there was no significant reduction in heart rate and diastolic pressure (table 2), and the changes in the dominant frequency were less dramatic. However, the initial frequency in lead II was significantly raised (table 3 ), and remained significantly higher than in the control group for the first $160 \mathrm{~s}$ of fibrillation (fig 3). The data from the endocardial lead showed a similar time course. Although the initial endocardial dominant frequency did not differ significantly from the corresponding "no drug" data (table 3 ), the dominant frequency at $80 \mathrm{~s}$ was significantly larger (fig 4).

The mean peak power of ventricular fibrillation from lead II was similar in the two verapamil groups and the "no drug" group (table 3). However after the higher dose of verapamil the mean peak power from the endocardium was lower than in the "no drug" group. After verapamil, the $-10 \mathrm{~dB}$ bandwidth increased significantly in the endocardium after both the high and low doses and in lead II after the high dose suggesting increased fractionation of the fibrillation waveform.

\section{Discussion}

These analyses of the ECG waveform of ventricular fibrillation show that most of the power of the fibrillation signal is contained within a small range of frequencies, some $6-10 \mathrm{~Hz}$ in the pig, which is slower than in the dog (8-15 $\mathrm{Hz}){ }^{6}{ }^{19}$ Comparison of these analyses showed similar dominant frequencies and time courses for body surface and endocardial ECG records in the pigs, as in a previous study in mongrel dogs. ${ }^{19}$ During ventricular fibrillation in pig and dog myocardium, activation fronts are about $120-130 \mathrm{~ms}$ apart, stimulating the myocytes at a rate of $7-9 \mathrm{~Hz}^{1}$ In the cat heart cycles of
90-100 ms shortening to $50-60 \mathrm{~ms}$ are seen during fibrillation. ${ }^{2}$ These short cycles correspond to the dominant frequencies of ventricular fibrillation reported in the present and previous studies.

The fast Fourier transform has several wellrecognised limitations. ${ }^{26}$ We have sought to minimise these artefacts by recording with an anti-aliasing filter at $44 \mathrm{~Hz}$ and using a highly developed scientific instrument for the frequency analysis. The effects of frequency leakage, which would slur and widen the definition of the central frequency, were reduced by a Hanning window, to give a more rounded end point to the series of samples. The ECG of ventricular fibrillation is ideally suited to this type of analysis because it is a continuous rhythm disturbance. Hence the power spectrum permits the assessment of the relative contributions to the ECG of different frequencies over a reasonable period of time. No difference was seen in the amplitude of the ECG signal, which indicates the coarseness or fineness of the signal.

The physiological basis of the power spectrum of ventricular fibrillation is contentious. Since the report of Nygards and Hulting in $1977^{4}$ several groups have analysed the frequency spectrum of fibrillation. Most interestingly Goldberger et $a l^{5}$ have suggested that the narrow power spectrum of ventricular fibrillation indicates some ordering, possibly representing deterministic chaos. This has been disputed by Kaplan and Cohen, ${ }^{27}$ who found little difference between fibrillation and a nonchaotic random signal.

The frequency of ventricular fibrillation may be crucial in determining the success of resuscitation. ${ }^{7}$ Over the first $400 \mathrm{~s}$ of ventricular fibrillation, the mean dominant frequency did not fall significantly in untreated pigs. This contrasts with the rapid drop in dominant frequency seen in the unperfused dog myocardium after $60-90$ s. $^{3619}$ Brown et al have also reported that the median frequency of fibrillation did not drop in the pig myocardium, but increased to about $13 \mathrm{~Hz}$ after $4 \mathrm{~min}$ of fibrillation, and then fell slowly over a further 10 min. ${ }^{22}$ In this respect ventricular fibrillation in the pig, rather than the dog, may be more typical of clinical fibrillation in man.?

\section{DRUGS ACTING ON VOLTAGE-DEPENDENT}

SODIUM CHANNELS

All of the sodium channel blocking drugs tested reduced the dominant frequency of the fibrillation waveform. However, the class IB drugs did this most dramatically.

The rate and voltage-dependent blockade of sodium channels by class I antiarrhythmic drugs causes a slower maximum rate of depolarisation..$^{128}$ Individual cardiac myocytes are more difficult to stimulate and the conduction velocity in the myocardium drops. ${ }^{11}$ These drugs show significant differences in the kinetics of the onset and offset of their interaction with the sodium channels. ${ }^{12} 12$ It is difficult to study the effects of stimulation rates as high as those found during ventricular fibrillation, none the less some of these kinetic data were obtained from canine Purkinje fibres stimulated 
at $5 \mathrm{~Hz},{ }^{12}$ close to the dominant frequency of ventricular fibrillation in the present study.

In the present study lignocaine and mexiletine had no significant electrophysiological effect during resting sinus rhythm (despite high plasma concentrations) but reduced the dominant frequency of fibrillation to about half that in the control group. This reduction was maintained throughout the $400 \mathrm{~s}$ period of fibrillation. The bandwidth of frequencies around this dominant frequency also fell. These drugs raised the threshold for induction of fibrillation by trains of stimuli, as previously reported. ${ }^{24} 29$ Class IB drugs have larger effects at fast stimulation rates and show a rapid onset of action. ${ }^{10} 12$ Lignocaine also increases the threshold energy required to achieve successful defibrillation, ${ }^{30}$ possibly because effective sodium channel blockade during ventricular fibrillation increases the current required to depolarise a critical mass of myocardium and achieve successful defibrillation.

Pre-treatment with disopyramide $(2.5 \mathrm{mg})$ $\mathrm{kg}{ }^{23}$ gave a plasma concentration at the low end of the therapeutic range $(2-8 \mu \mathrm{g} / \mathrm{ml})^{31}$ and reduced the dominant frequency of fibrillation in lead II and the endocardium to a similar extent as the class IB drugs. In the greyhound this dose $(2.5 \mathrm{mg} / \mathrm{kg})$ was effective in preventing ventricular arrhythmias and fibrillation after ligation of a coronary artery, despite causing a reduction in cardiac output. ${ }^{32}$ Disopyramide differs from lignocaine and mexiletine in that it binds to the voltage-dependent sodium channels in the open state. ${ }^{10}$

In contrast, the class IC drug flecainide $(3 \mathrm{mg} / \mathrm{kg}$ ) was the least potent of the class I drugs, and did not significantly reduce the dominant frequency of fibrillation for the initial 0-40 s period, despite a high plasma concentration (therapeutic range $0.8-1.6 \mu \mathrm{g} / \mathrm{ml}$ ). ${ }^{31}$ Though this may reflect the slower onset kinetics attributed to this subgroup of drugs, the time scale for action is much longer than their reported dissociation constants. ${ }^{12}$ Cardiac effects, with a modest fall in systolic blood pressure and increase in the duration of the QRS complex compared with pre-drug values were noted after flecainide in the present study. Treatment of pigs with the same dose of flecainide $(2 \mathrm{mg} / \mathrm{kg})$ reduced cardiac output and prevented ventricular tachycardia and fibrillation due to acute myocardial ischaemia. ${ }^{25}$ However, flecainide can cause some blockade of L-type $\mathrm{Ca}^{++}$channels in the heart ${ }^{33}$ which, by analogy with the effects of verapamil, may maintain or increase the frequency of fibrillation.

Alterations in the duration of the action potentials and effective refractory periods induced by these drugs do not seem to have been important in determining the frequency of ventricular fibrillation in the present study. A shortening of the action potential duration, as with the class IB drugs lignocaine and mexiletine, could facilitate high frequency activity. The converse would certainly be expected of class IA drugs, such as disopyramide, which lengthen the action potential duration. However in the present study, all of the class I drugs acted in a similar manner, suggesting that their predominant action is blockade of the voltage-dependent sodium channels, and that the nature and extent of this interaction and various pharmacokinetic considerations determine their potency.

Effects of verapamil

In the present study verapamil had two effects on ventricular fibrillation. Firstly it increased the dominant frequency of ventricular fibrillation in a dose dependent manner. With the higher dose of verapamil, the frequency peaked at about $16 \mathrm{~Hz}$, nearly twice the frequency in the control group. A similar result was reported in ventricular fibrillation in dogs treated with verapamil ${ }^{34}$ or nifedipine. ${ }^{19}$ Secondly the bandwidth of frequencies around this dominant frequency was increased after verapamil in both the endocardium and myocardium.

Two explanations can be offered for this effect of verapamil on the frequency of fibrillation. The first is that the increased frequency of fibrillation is an electrophysiological effect-a shortening of action potential duration caused by blockade of the L-type inward calcium channel. Although verapamil shortened the duration of the plateau of the action potential in canine Purkinje fibres $\left(\mathrm{APD}_{50 \%}\right)$ it did not have much effect on ventricular muscle fibres. ${ }^{35}$ However, the action potential duration in both Purkinje and ventricular fibres showed alternation to a lesser extent after a sudden increase in stimulation rate when pre-treatment with verapamil was given. Hence shortening of the action potential duration after verapamil is minimal and does not fully explain the marked rise and subsequent fall in the dominant frequency of fibrillation observed in this study with the higher dose of verapamil.

In acutely ischaemic myocardium verapamil reduces conduction delay in both $\operatorname{dog}^{36-38}$ and pig. ${ }^{39}$ Verapamil also prevents the development of ventricular fibrillation after coronary artery ligation in pig $^{20}$ and $\operatorname{dog}^{3640}$ and increases the threshold current for fibrillation in the ischaemic dog heart. ${ }^{37} 38$ Calcium blockade preserves myocardial metabolism in ischaemic ventricular tissue. ${ }^{213941}$ In the ischaemic pig heart the leakage of potassium and accumulation of $\mathrm{H}+$ are reduced and delayed by pretreatment with verapamil. ${ }^{39}$

Previous studies have shown that pretreatment with calcium channel blocking drugs prevents post-defibrillation dysfunction and improves resuscitation from ventricular fibrillation of $120-150 \mathrm{~s}$ duration. ${ }^{18}{ }^{19}$ Hence an alternative explanation is that verapamil acts in a cardioprotective manner by blocking the marked influx and accumulation of calcium seen in the myocyte during fibrillation. ${ }^{1617}$ This would preserve high energy phosphates, improve the excitation-coupling processes, and could explain the rise in frequency over the first 80-120 s of fibrillation. Prevention of calcium accumulation would also reduce cell uncoupling at nexuses, ${ }^{42}$ which was suggested as the most likely mechanism in the dog heart. ${ }^{34}$ The fall in the dominant frequency of fibrillation to corresponding control values after $240 \mathrm{~s}$ would 
then represent the advent of intracellular calcium overload, as verapamil may only partially reduce the influx of calcium. Hence these drugs are cardioprotective only in the first few minutes of ventricular fibrillation.

Not all of the effects of verapamil on ventricular fibrillation are beneficial. Despite an increase in the frequency of the fibrillation waveform the administration of verapamil caused a dose-related rise in the threshold energy needed for internal defibrillation. ${ }^{43}$ The widening of the bandwidth of fibrillation frequencies observed in the present study indicates an increase in fractionation of the fibrillation wavefronts, and could account for this adverse effect of verapamil on defibrillation.

This study showed that blockade of the sodium channel during ventricular fibrillation results in a slowing of the fibrillation waveform. The converse is true for calcium channel blockade, which causes a faster fibrillation frequency, but with greater fractionation of the fibrillation wavefronts in the heart.

AJS was a Royal Victoria Hospital Research Fellow. This work received a generous grant from the Northern Ireland Chest, Heart and Stroke Association.

1 Janse MJ, van Capelle FJL, Morsink H, Kléber AG, WilmsSchopman F, Cardinal R, et al. Flow of "injury" current and patterns of excitation during early ventricular and patterns of excitation during early ventricular arrhythmias in acute regional myocardial ischemia in iso-
lated porcine and canine hearts. Circ Res 1980;47: lated porci

2 Pogwizd SM, Corr PB. Mechanisms underlying ventricular tachycardia and fibrillation in the ischemic heart: relation to nonlinear dynamics. Ann NY Acad Sci 1990;591: 278-300.

3 Ideker RE, Klein GJ, Harrison L, Smith WM, Kasell J, Reimer KA, et al. The transition to ventricular fibrillation induced by reperfusion after acute ischemia in the dog: a period of organised epicardial activation. Circulation 1981;63:1371-9.

4 Nygards $M$, Hulting J. Recognition of ventricular fibrillation utilizing the power spectrum of the ECG. IEEE Computers in Cardiology 1977;4:393-7.

5 Goldberger AL, Bhargava V, West BJ, Mandell AJ. Some observations on the question: is ventricular fibrillation "chaos"? Physica 1986;19D:282-9.

6 Carlisle EJF, Allen JD, Kernohan WG, Anderson J, Adgey AAJ. Fourier analysis of ventricular fibrillation of varied aetiology. Eur Hearn $\mathcal{f}$ 1990;11:173-81.

7 Stewart AJ, Allen JD, Adgey AAJ. Frequency analysis of ventricular fibrillation and resuscitation success. Quart $\mathcal{J}$ Med 1992;85:761-9.

8 Clayton RH, Murray A, Campbell RWF. Changes in the surface electrocardiogram during the onset of spontaneous ventricular fibrillation in man. Eur Heart $f$ 1994;15:184-8.

9 Clayton RH, Murray A, Campbell RWF. Analysis of the body surface ECG measured in independent leads during ventricular fibrillation in humans. PACE 1995;18: 1876-81.

10 Task Force of the Working Group on Arrhythmias. The Sicilian gambit: a new approach to the classification of Sicilian gambit: a new approach to the classification of
antiarrhythmic drugs based on their actions on arrhythantiarrhythmic drugs based on their actions on arr
mogenic mechanisms. Circulation 1991;84:1831-51.

mogenic mechanisms. Circulation 1991;84:1831-51.
11 Davis J, Matsubara T, Scheinman MM, Katzung B, Hondeghem LH. Use-dependent effects of lidocaine on conduction in canine myocardium: application of the conduction in canine myocardium: application of the modulated

12 Pallandi RT, Campbell TJ. Selective depression of conduction of premature action potentials in canine Purkinje fibres by class Ib antiarrhythmic drugs: comparison with Ia and Ic drugs. Cardiovasc Res 1988;22:171-8.

13 Vaughan Williams EM. A classification of antiarrhythmic actions reassessed after a decade of new drugs. $\mathcal{F}$ Clin Pharmacol 1984;24:129-47.

14 Grant AO, Wendt DJ. Blockade of ion channels by antiarrhythmic drugs. $\mathcal{f}$ Cardiovasc Electrophysiol 1991;2:suppl S153-S68.

15 Merillat JC, Lakatta EG, Hano O, Guarnieri T. Role of calcium and the calcium channel in the initiation and maintenance of ventricular fibrillation. Circ Res 1990;67: 1115-23.

16 Kojima S, Wikman-Coffelt J, Wu ST, Parmley WW. Nature of $[\mathrm{Ca}++]$ transients during ventricular fibrillation and quinidine treatment in perfused rat hearts. $A m \mathcal{F}$ Physiol 1994;266:H1473-84.
17 Koretsune Y, Marban E. Cell calcium in the pathophysiology of ventricular fibrillation and in the pathogenesis of postarrhythmic contractile dysfunction. Circulation 1989 80:369-79.

18 Vincent J, Goldstein J, Dufaye P, Domb $M$ Electromechanical dissociation after ventricular fibrillation: prevention with calcium-entry blockers. $\mathcal{F}$ Cardiovasc Pharmacol 1984;6:1124-31.

19 Martin G, Cosin J, Such M, Hernandez A, Llamas P. Relation between power spectrum time course during ventricular fibrillation and electromechanical dissociation. Effects of coronary perfusion and nifedipine. Eur tion. Effects of coron
Heart $\mathcal{f} 1986 ; 7: 560-9$.

20 Muller CA, Opie LH, Hamm CW, Peisach M, Pineda CA Thandroyen FT. Verapamil and tiapamil in prevention of ventricular fibrillation in pigs with coronary ligation. Circulation 1988;78:227-32.

21 Jenkins MG, Johnson TA, Engle C, Gettes LS. Metabolic protection by verapamil during graded coronary flow reduction independent of effect on baseline systolic function. Circulation 1989;80:1870-7.

22 Brown CG, Dzwonczyk R, Werman HA, Hamlin RI Estimating the duration of ventricular fibrillation. $A n$ Emerg Med 1989;18:1181-5.

23 Pedersen LE, Hermansen K, Olesen HP, Rasmussen SN The pharmacokinetics and protein binding of disopyramide in pigs. Acta Pharmacol Toxicol 1986;58:282-8.

24 Vogt B, Martin C, Meesmann W. Prophylactic lidocaine: concentrations in plasma and myocardial tissue and concentrations in plasma and myocardial tissue and antifibrillatoric efficacy during early ischemia
pigs. $₹$ Cardiovasc Pharmacol 1988;12:571-8.

25 Verdouw PD, Deckers JW, Conard GJ. Antiarrhythmic and hemodynamic actions of flecainide acetate $(R-818)$ in the ischemic porcine heart. $\mathcal{f}$ Cardiovasc Pharmacol 1979;1 473-86.

26 Stearns SD, Hush DR. Digital signal analysis. Englewood Cliffs, NJ: Prentice-Hall International, 1990.

27 Kaplan DT, Cohen RJ. Is fibrillation chaos? Circ Res 1990 67:886-92.

28 Rosen MR, Hoffman BF, Wit AL. Electrophysiology and pharmacology of cardiac arrhythmias. V. Cardiac antiarrhythmic effects of lidocaine. Am Heart $\mathcal{f} 1975 ; 89$ : 526-36.

29 Allen JD, James RGG, Kelly JG, Shanks RG, Zaidi SA Comparison of the effects of lignocaine and mexiletine on experimental ventricular arrhythmias. Postgrad Med $\mathscr{Y}$ on experimental ventricular

30 Echt DS, Black IN, Barbey JT, Coxe DR, Cato E. Evaluation of antiarrhythmic drugs on defibrillation energy requirements in dogs: sodium channel block and energy requirements in dogs: sodium channel block and
action potential prolongation. Circulation 1989;79. action pote

31 Echt DS, Mason JW. Management of serious cardiac arrhythmias with drugs. In: Conti CR, ed. Cardiovascular Clinics 14/3: Cardiac drug therapy. Philadelphia: FA Davis Company, 1984;191-209.

32 Marshall RJ, Parratt JR. The effects of disopyramide phosphate on early post-coronary artery ligation dysrhythmias and on epicardial ST-segment elevation in anaesthetized dogs. Br $\mathcal{F}$ Pharmacol 1979;66:241-50.

33 Scamps F, Undrovinas A, Vassort G. Inhibition of $\mathrm{I}_{\mathrm{Ca}}$ in single frog cardiac cells by quinidine, flecainide, ethmozin, and ethacizin. Am f Physiol 1989;256:C549-59.

34 Carlisle EJF, Allen JD, Kernohan WG, Leahey WA, Adgey AAJ. Pharmacological analysis of established ventricular Aibrillation. Br f Pharmacol 1990;100:530-4.

35 Hirata Y, Kodama I, Iwamura N, Shimizu T, Toyama J, Yamada K. Effects of verapamil on canine Purkinje fibres and ventricular muscle fibres with particular reference to and ventricular muscle fibres with particular reference to the alternation of action potential duration after a sudd
increase in driving rate. Cardiovasc Res 1979;13:1-8.

36 Elharrar V, Gaum W, Zipes D. Effect of drugs on conduction delay and incidence of ventricular arrhythmia induced by acute coronary occlusion in dogs. $\mathrm{Am} f$ Cardiol 1977;39:544-9.

37 Fondacaro JD, Han J, Yoon MS. Effects of verapamil on ventricular rhythm during acute coronary occlusion. $A m$ Heart 7 1978;96:81-6.

38 Gulker H, Thale J, Haverkamp W, Hindricks G, Holtschule A, Mann B, et al. Time course of ventricular arrhythmias, fibrillation thresholds and epicardial conduction delays following acute coronary artery occlusion and release-its modification by verapamil. In: Fleckenstein $\mathrm{A}$, Laragh JH, eds. Hypertension-the next Fleckenstein A, Laragh JH, eds. Hypertension-the next
decade. Edinburgh: Churchill-Livingstone, 1987; 237-44.

39 Fleet WF, Johnson TA, Graebner CA, Engle CL, Gettes LS. Effects of verapamil on ischemia-induced changes in extracellular $\mathrm{K}^{+}, \mathrm{pH}$ and local activation in the pig. Circulation 1986;73:837-46.

40 Sherman LG, Liang CS, Boden WE, Hood WB Jr. The effect of verapamil on mechanical performance of acutely ischemic and reperfused myocardium in the conscious dog. Circ Res 1981;48:224-32.

41 Auffermann W, Wagner S, Wu S, Buser P, Parmley WW Wikman-Coffelt J. Calcium inhibition of glycolysis contributes to ischaemic injury. Cardiovasc Res 1990;24 510-20.

42 Dahl G, Isenberg G. Decoupling of heart muscle cells: correlation with increased cytoplasmic calcium activity and with changes of nexus ultrastructure. $\mathcal{F}$ Memb Biol 1980 53:63-75

43 Schräder R, Brooks $M$, Echt DS. Effects of verapamil and Bay K8644 on defibrillation energy requirements in dogs. f Cardiovasc Pharmacol 1992;19:839-50. 